\title{
Improvement of photocatalytic decomposition of methyl orange by modified MWCNTs, prediction of degradation rate using statistical models
}

Sedigheh Abbasi ( $\nabla$ s.abbasi@esfarayen.ac.ir)

Esfarayen University of Technology https://orcid.org/0000-0002-2546-5512

\section{Research Article}

Keywords: TiO2 nanoparticles, Modified MWCNTs, Analysis of variance, Graphical method, Adequacy

Posted Date: February 22nd, 2021

DOI: https://doi.org/10.21203/rs.3.rs-173199/v1

License: (c) (1) This work is licensed under a Creative Commons Attribution 4.0 International License.

Read Full License 


\section{Abstract}

Multi-walled carbon nanotubes (MWCNTs) have been successfully modified with TiO2 nanoparticles via a two-step hydrolysis technique. Firstly, the pristine MWCNTs are functionalized in nitric acid (HNO3) to creation of oxygen containing groups. Secondly, TiO2 nanoparticles are synthesized on the surface of functionalized MWCNTs through hydrolysis method. The synthesized samples have been used as photocatalyst for decomposition of methyl orange (MO) as dye organic pollutant. The characterization of samples using x-ray diffraction pattern (XRD) confirm the presence of $\mathrm{TiO} 2$ nanoparticles with mixture of anatase and rutile phases. Regarding the photocatalytic performance of TiO2 nanoparticles and modified MWCNTs with $\mathrm{TiO} 2$ nanoparticles, it observed that the degradation rate of $\mathrm{MO}$ increases by increasing the irradiation time from $5 \mathrm{~min}$ to $35 \mathrm{~min}$. The variation of degradation rate upon $\mathrm{pH}$ of suspension reveals that the maximum and minimum degradation rate are in acidic $(\mathrm{pH}=3)$ and neutral condition $(\mathrm{pH}=7)$. Meanwhile, the results show that the presence of MWCNTs leads to the enhancement of degradation rate. The analysis of variance (ANOVA) results confirm that both of main factors (irradiation time and $\mathrm{pH}$ ) and their interaction have a significant influence on the degradation rate of $\mathrm{MO}$. However, the effect of irradiation time is more than that of $\mathrm{pH}$ and their interaction. The graphical methods verify the quality and adequacy of the statistical models for prediction of the degradation rate.

\section{Introduction}

The elimination of organic contaminates from wastewater of industries is a major problem in the recent decades. The application of semiconductor photocatalysts is a new approach for decomposition of organic pollutants $[1,2]$. In this technique, a light source with energy higher than the band gap of used semiconductors is applied [3]. The irradiation of the semiconductors leads to the migration of electrons that are located in the valence band to the conduction band. The transmittance of electrons causes the formation of electrons and holes in the valence band and conduction layer, respectively $[1,4]$. The formed electrons and holes are able to react by water and oxygen. The reaction among them causes the creation of different kinds of radical species that can act as decomposer of organic molecules $[5,6]$. The recombination of the formed electrons and holes can restrict the removal efficiency of pollutants. Therefore, the photocatalytic performance of the semiconductor photocatalysts depends on the separation efficiency of produced charges [7]. According to the previous reports, there are several methods that can be applied for the decreasing of recombination rate of produced charges. For example, the doping of materials that can act as electron sinks (such as $\mathrm{Ag}$ and $\mathrm{Au}$ ) on the surface of photocatalysts $[8,9]$. The other technique for decreasing the recombination rate of electrons and holes is application of a specific support with high surface area such as multi-walled carbon nanotubes (MWCNTs) and graphene oxide (GO) [10]. The synthesis of photocatalysts on the surface of these materials as template can significantly enhance the photocatalytic performance. It can be attributed to the effect of MWCNTs and GO on the migration rate of electrons from valence band [11,12]. The coupling of semiconductor oxides to the carbon supports can decrease the recombination of electrons and holes. Meanwhile, it has a synergistic effect on the enhancement of energy range that stimulates electrons [13]. 
Among the most widely used semiconductor photocatalysts, $\mathrm{TiO}_{2}$ has been received great attention due to its excellent photocatalytic performance, environmental compatibility, low cost and wide band gap [14, 15]. In the recent years, several coupled photocatalysts such as GO-ZnO[16], CNT-ZnO [4, 6, 17], $\mathrm{Fe}_{3} \mathrm{O}_{4}-\mathrm{GO}$ $\mathrm{ZnO}$ [12], $\mathrm{CNT}-\mathrm{TiO}_{2}$ [2] and $\mathrm{SnO}_{2}-\mathrm{CNT}$ [13] report the augmentation of photocatalytic activity for degradation of numerous organic pollutants. Despite extensive research on the removal of numerous organic pollutants, no statistical study of the impact of acidity on the removal of dye organic pollutants has been performed using modified MWCNTs with $\mathrm{TiO}_{2}$.

The main purpose of this research is synthesis of $\mathrm{TiO}_{2}$ nanoparticles and coupled of $\mathrm{MWCNTs}-\mathrm{TiO}_{2}$ as photocatalyst for degradation of methyl orange (MO). The synthesized photocatalysts are characterized

by means of X-ray diffraction pattern (XRD). The influence of experimental factors such as illumination time and $\mathrm{pH}$ of suspension are investigated on the photocatalytic performance of the samples. The experimental results are analyzed based on the analysis of variance (ANOVA) and response surface methodology (RSM). The influence of main factors and their interaction on the degradation rate of MO are studied. Finally, the adequacy of the presented statistical models for the prediction of degradation rate is investigated based on the graphical method.

\section{Experimental}

\subsection{Chemicals}

MWCNTs with average diameter about 40-60 nm and length 5-15 $\mu \mathrm{m}$ are purchased as support material. Nitric acid $\left(\mathrm{HNO}_{3}, 65 \%\right)$, Tetra chloride titanium $\left(\mathrm{TiCl}_{4}, 99 \%\right)$ and Methyl orange (99.5\%) with analytical grade are applied without any purification. All of aqueous suspensions are based on distilled water. Hydrochloric acid $(\mathrm{HCl}, 99 \%)$ and sodium hydroxide $(\mathrm{NaOH}, 99 \%)$ are used to adjust the $\mathrm{pH}$ of the suspensions.

\subsection{Preparation of photocatalysts}

Synthesis procedure of $\mathrm{TiO}_{2}$ nanoparticles as applied photocatalysts is same as method that is described in our previous reports $[14,18]$. The preparation of modified MWCNTs with $\mathrm{TiO}_{2}$ nanoparticles consists of two steps including functionalization of MWCNTs and surface decoration with $\mathrm{TiO}_{2}$ nanoparticles. The functionalization step is performed using acid-treatment process. For this purpose, $0.1 \mathrm{~g}$ of as received MWCNTs is dispersed in $50 \mathrm{ml}$ of $\mathrm{HNO}_{3}$ and is agitated for 120 min using a magnetic stirrer. Then the suspension is transferred to an ultrasonic bath and the treatment process is continues for $120 \mathrm{~min}$. Finally, the treated MWCNTs are filtered, washed and dried at $80^{\circ} \mathrm{C}$ for an overnight. The second step is based on the hydrolysis method to synthesis of $\mathrm{TiO}_{2}$ nanoparticles on the surface of the prepared functionalized MWCNTs. $0.04 \mathrm{~g}$ of dried acid treated MWCNTs is dispersed in $100 \mathrm{ml}$ of distilled water and is agitated for $30 \mathrm{~min}$. Then, $0.4 \mathrm{ml}$ of $\mathrm{TiCl}_{4}$ is added to the mixture at room temperature and mixed for about $5 \mathrm{~h}$. Subsequently, the temperature of mixture is raised to $65^{\circ} \mathrm{C}$ and maintained for $12 \mathrm{~h}$. Finally, the mixture is filtered and washed. The prepared dried powder is calcined at $350^{\circ} \mathrm{C}$ for $3 \mathrm{~h}$. 


\subsection{Experimental procedure for photocatalytic decomposition of $M O$}

The photocatalytic experiments for decomposition of $\mathrm{MO}$ are carried out in a batch reactor in three $\mathrm{pH}$ $(\mathrm{pH}=3, \mathrm{pH}=7$ and $\mathrm{pH}=11)$. The temperature of the suspension in the reactor is controlled using circulation of water. The $\mathrm{MO}$ suspension $(10 \mathrm{mg} / \mathrm{ml})$ is located at a dark chamber for $60 \mathrm{~min}$. Then, the initial concentration of $\mathrm{MO}\left(\mathrm{C}_{0}\right)$ that is attributed to the initial adsorption intensity $\left(\mathrm{A}_{0}\right)$ is recorded by means of a Lambda EZ 201spectrophotometer (Perkin Elmer Company). The suspension is irradiated using a UV lamp (150W). Every 5 minutes, some of suspension is discharged and filtered. The remained concentration of $\mathrm{MO}\left(\mathrm{C}_{t}\right)$ in the suspension can be evaluated by recording the adsorption at each interval $\left(A_{t}\right)$. The degradation rate of pollutant can be expressed by. The statistical investigations based on the analysis of variance (ANOVA) is performed using design of experiment (DOE).

\section{Results And Discussion}

\subsection{XRD analysis}

The XRD pattern of the synthesized $\mathrm{TiO}_{2}$ nanoparticles is illustrated in Fig. 1 for investigation of crystal structure. Based on this Figure, it can be observed that the synthesized $\mathrm{TiO}_{2}$ nanoparticles have two main phases such as anatase and rutile. The diffraction peaks that are referred to the anatase phase and rutile phase are labeled using different symbols. So that, the observed sharp characteristic peaks that is located at $2=25.35^{\circ}, 37.96^{\circ}, 48.02^{\circ}, 62.89^{\circ}$ and $75.20^{\circ}$ are assigned to the (101), (004), (200), (204) and (215) crystal orientations of the anatase phase of synthesized titania. The diffraction peaks at $27.33^{\circ}$, $36.26^{\circ}, 41.36^{\circ}, 54.39^{\circ}, 56.66^{\circ}, 62.26^{\circ}, 68.98^{\circ}$ and $70.11^{\circ}$ belong to the (110), (101), (111), (211), (220), (002), (301) and (112) planes of $\mathrm{TiO}_{2}$ nanoparticles with rutile crystal structure. Therefore, the both of crystal structures (anatase and rutile) can be confirmed in the synthesized $\mathrm{TiO}_{2}$ nanoparticles. The fraction of each crystal structures can be approximately calculated using Equation $1[19,20]$ :

$$
\% \mathrm{~A}=\frac{\mathrm{I}_{\mathrm{A}}}{\mathrm{I}_{\mathrm{A}}+1.265 \mathrm{I}_{\mathrm{R}}} \times 100
$$

Where, $A$ is the amount of titania with anatase crystal structure. $I_{A}$ and $I_{R}$ are corresponded to the intensity of the main characteristic peaks of anatase (101) and rutile (211) phases, respectively. Therefore, according to this equation the amount of anatase and rutile crystal structures are about to $63 \%$ and $37 \%$, respectively.

The XRD pattern of functionalized MWCNTs using nitric acid is presented in Fig. 2. The main characteristic peaks of MWCNTs that is belonged to the (002) and (100) Bragg reflection planes of graphite can be detected at $26.31^{\circ}$ and $42.76^{\circ}$, respectively $[19,21]$. Fig. 3 illustrates the XRD pattern of the modified MWCNTs with $\mathrm{TiO}_{2}$ nanoparticles. This Figure suggests the formation of the both phases of 
anatase and rutile crystallites. As can be seen, the major peaks of the synthesized $\mathrm{MWCNTs}^{-\mathrm{TiO}_{2}}$ are located at about $25.33^{\circ}, 27.16^{\circ}, 36.14^{\circ}, 37.85^{\circ}, 47.95^{\circ}, 54.16^{\circ}, 62.35^{\circ}$ and $68.51^{\circ}$. The observed diffraction peaks at $25.33^{\circ}, 37.85^{\circ}, 47.95^{\circ}, 54.16^{\circ}$ and $62.35^{\circ}$ are corresponded to the (101), (004), (200), (105) and (204) crystal facets of anatse $\mathrm{TiO}_{2}$, respectively [15]. Meanwhile, the located peaks at $27.16^{\circ}$, $36.14^{\circ}, 54.16^{\circ}, 62.35^{\circ}$ and $68.51^{\circ}$ are indexed to the (110), (101), (211), (002) and (301) planes of rutile $\mathrm{TiO}_{2}$, respectively [14]. The main characteristic peaks of MWCNTs are not detectable in the XRD pattern of the modified MWCNTS with $\mathrm{TiO}_{2}$. It can be due to the overlap of diffraction peak of (002) plane of MWCNTs which is located at $26.11^{\circ}$ and sharp peak of (101) plane of anatase $\mathrm{TiO}_{2}$.

\subsection{The study of MO degradation rate}

Fig. 4 and Fig. 5 show the variation of $\mathrm{MO}$ concentration with respect to the irradiation time and $\mathrm{pH}$ using $\mathrm{TiO}_{2}$ nanoparticles and modified MWCNTs, respectively. Given the trend of concentration changes, it can be observed that the ratio of final to initial concentration of $\mathrm{MO}$ decreases by increasing of UV irradiation time (this behavior is the same at all of the studied $\mathrm{pH}$ ). The main reason for the decrease in pollutant concentration over time is the amount of created electron-hole pairs. When the photocatalysts are exposed to the UV radiation, the electrons in the valence layer are excited. The excitation of electrons causes the electrons to move from the valence layer to the conduction layer [18, 22]. Electron displacement causes the formation of electrons and holes in the valence layer and conduction layer, respectively. The formed electron- hole pairs can react with water and dissolved oxygen in the suspension containing pollutants and produce the oxidizing radicals such as and, respectively. These types of oxidizing radicals can successfully degrade and decompose the organic pollutants. Therefore, the decomposer radicals can be enhanced with increasing the irradiation time $[11,23]$. The results of the effect of $\mathrm{PH}$ on methyl orange concentration show that the acidic medium have the greatest effect on the removal of pollutant. However, in neutral medium the rate of degradation of methyl orange is lower than that of acidic and alkaline conditions. The high rate of decomposition of methyl orange in the acidic medium is attributed to the presence of hydrogen ions $\left(\mathrm{H}^{+}\right)$. The $\mathrm{H}^{+}$ions in the suspension can react with the produced electrons $\left(\mathrm{e}^{-}\right)$and form the hydrogen radicals $(\mathrm{H} \cdot)$. Finally, the derived radicals can adsorb the oxygen of the solution and produce the $\mathrm{OH} \cdot[15,24]$. Therefore, it can be deduced that as the number of hydrogen ions (in acidic medium) increases, the number of decomposing radicals also increases. The efficiency of $\mathrm{MO}$ removal using a photocatalyst is affected by the surface charge of the photocatalyst. This is because as the surface charge of the photocatalyst increases, the dispersion of the photocatalyst in the suspension increases. Therefore, a higher level of photocatalyst is exposed to the UV radiation. This increases the amount of electron excitation and oxidizing radicals. Therefore, due to the reduction of the surface charge of the photocatalyst under neutral conditions $(\mathrm{pH}=7)$, the removal rate of the $\mathrm{MO}$ under neutral conditions is less than the acidic and alkaline conditions [25]. 
Fig. 6 illustrates the comparison between variation of $\mathrm{MO}$ concentration with respect to the irradiation time using $\mathrm{TiO}_{2}$ nanoparticles and modified MWCNTs at different $\mathrm{pH}$. The presented results show that the concentration of methyl orange at each time point of irradiation and all three $\mathrm{pH}$ when using modified MWCNTs is lower than $\mathrm{TiO}_{2}$ nanoparticles. Therefore, these results can confirm the positive effect of carbon nanotubes on methyl orange removal. The main role of carbon nanotubes is to reduce the agglomeration rate of $\mathrm{TiO}_{2}$ nanoparticles. Therefore, a higher level of photocatalyst can be exposed to the UV radiation [26, 27]. This causes the increasing of excitation electrons of valence band in the modified MWCNTs with $\mathrm{TiO}_{2}$ nanoparticles photocatalyst. The enhancement of the excited electrons leads to the increasing of transmitted electrons from valence band to the conduction band. Therefore, more hydroxyl radicals are produced in the suspension containing modified MWCNTs as photocatalyst. Thus it can be confirmed that the removal rate of methyl orange by modified MWCNTs is substantially higher than $\mathrm{TiO}_{2}$ nanoparticles.

\subsection{The analysis of variance study}

Table 1 and Table 2 present the results of analysis of variance for $\mathrm{MO}$ degradation rate using $\mathrm{TiO}_{2}$ nanoparticles and modified MWCNTs with $\mathrm{TiO}_{2}$ nanoparticles, respectively. It can be seen that the degree of freedom ( $\mathrm{Df}$ ) for factor $\mathrm{A}$ (irradiation time) and factor $\mathrm{B}(\mathrm{pH})$ is equal to 6 and 2, respectively. Thus, the number of factor's levels of $A$ and $B$ is $7(5,10,15,20,25,30$ and $35 \mathrm{~min})$ and $3(\mathrm{pH}=3, \mathrm{pH}=7$ and $\mathrm{pH}=11)$, respectively. The $D f$ value for interaction between $A$ and $B(A B)$ is the $D f$ multiple of single factors. The importance of each single factor and their interactions can be evaluated using F-value and P-value. The significant parameters have the sum of square value more than error. Therefore, it can be deducted that the enhancement of F-value leads to the increasing of factor's importance [28, 29]. According to the Fvalues of presented factors in Table 1 and Table 2, it can be observed that all of the parameters have reasonable F-value. It means that both of main factors and their interaction have significant effect on the degradation rate of $\mathrm{MO}$. According to the results of F-value, it can be concluded that the variation of the factors' levels can reasonably vary the degradation rate of $\mathrm{MO}$. Based on the results of these Tables, it is clear that the F-value of factor $\mathrm{A}$ for degradation rate of $\mathrm{MO}$ using $\mathrm{TiO}_{2}$ nanoparticles and modified MWCNTs are 4981.66 and 10254.87, respectively. However, the F-value of factor B in Table 1 and Table 2 is 979.27 and 1495.84, respectively. The comparison between F-values of factor A and factor $B$ represents that irradiation time have F-value more than $\mathrm{pH}$. Meanwhile, as can be shown, the contribution percent of factor $\mathrm{A}$ on the $\mathrm{MO}$ degradation rate using $\mathrm{TiO}_{2}$ nanoparticles and modified MWCNTs is 93.37 and 95.11 , respectively. In addition, $6.12 \%$ and $4.62 \%$ of degradation rate of $\mathrm{MO}$ can be affected by $\mathrm{pH}$ of suspension containing $\mathrm{TiO}_{2}$ nanoparticles and modified MWCNTs, respectively. It shows that the influence of irradiation time on the degradation of $\mathrm{MO}$ is more than that of $\mathrm{pH}$. It may be due to the effect of irradiation time on the created electron hole pairs. Besides the F-value of factors, the significant factors can be distinguished based on the P-value. So that, each factor that have P-value less than the significance level () is assigned as a significant factor [30]. The results of Table 1 and Table 2 confirm 
that irradiation time, $\mathrm{pH}$ and their interaction have P-value less than 0.05 . Therefore, all of these parameters are assigned as significant factors. Therefore, there is not any insignificant factor. The results of Table 1 and Table 2 also confirm it. As can be observed, the Df and sum of square of lack of fit is zero. The lack of fit contain the insignificant parameters [31]. Therefore, it can be concluded that the proposed models in Table 1 and Table 2 involve only the significant factors. Thus the presented statistical models can accurately predict the variation of $\mathrm{MO}$ degradation rate with respect to the irradiation time, $\mathrm{pH}$ and their interaction.

Table 1. Analysis of variance for $\mathrm{MO}$ degradation rate using $\mathrm{TiO}_{2}$ nanoparticles.

\begin{tabular}{|llllllll|}
\hline Source & $\begin{array}{l}\text { Sum of } \\
\text { Square }\end{array}$ & Df & $\begin{array}{l}\text { Mean } \\
\text { Squares }\end{array}$ & F-Value & P-value & $\begin{array}{l}\% \\
\text { Contribution }\end{array}$ & \\
Model & 2.83 & 20 & 0.14 & 1598.45 & $<0.0001$ & - & significant \\
A (Time) & 2.64 & 6 & 0.44 & 4981.66 & $<0.0001$ & 93.37 & significant \\
B (pH) & 0.17 & 2 & 0.087 & 979.27 & $<0.0001$ & 6.12 & significant \\
AB & 0.011 & 12 & $8.872 \mathrm{E}-04$ & 10.03 & $<0.0001$ & 0.38 & significant \\
$\begin{array}{l}\text { Lack of } \\
\text { fit }\end{array}$ & 0 & 0 & - & - & -- & 0.000 & not \\
$\begin{array}{l}\text { Pure } \\
\text { error }\end{array}$ & $3.71 \mathrm{E}-03$ & 42 & $8.843 \mathrm{E}-05$ & - & -- & 0.13 & -- \\
\hline Total & 2.34 & 62 & - & - & - & -- & - \\
\hline
\end{tabular}

Table 2. Analysis of variance for $\mathrm{MO}$ degradation rate using modified $\mathrm{MWCNTs}$ with $\mathrm{TiO}_{2}$ nanoparticles.

\begin{tabular}{|llllllll|}
\hline Source & $\begin{array}{l}\text { Sum of } \\
\text { Square }\end{array}$ & Df & $\begin{array}{l}\text { Mean } \\
\text { Squares }\end{array}$ & F-Value & P-value & $\%$ \\
Contribution & \\
\hline Model & 3.07 & 20 & 0.15 & 3232.53 & $<0.0001$ & -- & significant \\
\hline A (Time) & 2.92 & 6 & 0.49 & 10254.87 & $<0.0001$ & 95.11 & significant \\
\hline $\mathrm{B}(\mathrm{pH})$ & 0.14 & 2 & 0.071 & 1495.84 & $<0.0001$ & 4.62 & significant \\
\hline AB & $6.15 \mathrm{E}-03$ & 12 & $5.12 \mathrm{E}-04$ & 10.80 & $<0.0001$ & 0.20 & significant \\
\hline $\begin{array}{l}\text { Lack of } \\
\text { fit }\end{array}$ & 0 & 0 & -- & -- & - & 0.000 & not \\
\hline $\begin{array}{l}\text { Pure } \\
\text { error }\end{array}$ & $1.99 \mathrm{E}-03$ & 42 & $4.74 \mathrm{E}-05$ & -- & - & 0.065 & - \\
\hline Total & 3.07 & 62 & -- & - & - & - & - \\
\hline
\end{tabular}


However, the quality of the both proposed models is justified by ANOVA tables; the assumptions that are applied for the application of ANOVA should be verified. The analysis of residuals based on the graphical technique is common for validation of degradation rate models of $\mathrm{TiO}_{2}$ nanoparticles and modified MWCNTs. The graphical approach can show the relationship between factors and response. In this method, the residuals are converted to the studentized residuals and are plotted versus main factors, run number or on normal probability [31,32]. The first assumption of the ANOVA is the normality of error that can be verified using normal probability plot. Fig. 7 and Fig. 8 illustrate the normal plot of residuals for degradation rate of $\mathrm{MO}$ using $\mathrm{TiO}_{2}$ nanoparticles and modified MWCNTs, respectively. The patterned distribution of studentized residuals around mean zero in Fig. 7 and Fig. 8 reveals the normality of errors for $\mathrm{TiO}_{2}$ nanoparticles and modified MWCNTs models. Thus, the degradation rate transformation is not required. Therefore, it can be deducted that both of the models can accurately fit the experimental degradation rates.

The second assumption in the ANOVA method is the independently distribution of error and constant variance of all studied factors and their levels [31]. The verification of this assumption can be carried out using the plotting of studentized residuals versus independent factors (such as irradiation time and $\mathrm{pH}$ of suspension), run number and predicted responses values that are estimated by model. The studentized residual plot versus time of irradiation and $\mathrm{pH}$ of suspension containing $\mathrm{TiO}_{2}$ nanoparticles are shown in Fig. 9 and Fig. 10, respectively. It is clear that all of the design points are located in the range of -3 and 3 . Therefore, it can be confirmed that there is not any outlier and discrepancy in design point of $\mathrm{TiO}_{2}$ nanoparticles. The same results can be observed in Fig. 11 and Fig. 12 for studentized residual plot versus time of irradiation and $\mathrm{pH}$ of suspension containing modified MWCNTs with $\mathrm{TiO}_{2}$ nanoparticles. Therefore, these results can verify the adequacy of the both statistical models for estimation of $\mathrm{MO}$ degradation rate with respect to the irradiation time and $\mathrm{pH}$.

The correlation between experimental data and predicted values that are obtained by statistical model of $\mathrm{TiO}_{2}$ nanoparticles and modified $\mathrm{MWCNTs}$ with $\mathrm{TiO}_{2}$ nanoparticles are presented in Fig. 13 and Fig. 14, respectively. Regarding these Figures, it can be observed that there is a good consistency among actuals and predicted degradation rate of $\mathrm{MO}$. Therefore, the adequacy of the both models for estimation of the degradation rate can be confirmed.

\subsection{The analysis of MO degradation rate based on response surface methodology}

The response surface method (RSM) is a three-dimensional approach for investigation of the response variation upon simultaneous influence of two factors [28]. Fig. 15 and Fig. 16 illustrate the response surface of $\mathrm{MO}$ degradation rate using $\mathrm{TiO}_{2}$ nanoparticles and modified $\mathrm{MWCNTs}$ with $\mathrm{TiO}_{2}$ nanoparticles, respectively. These two Figures show that the degradation rate of $\mathrm{MO}$ using both of photocatalysts increases by enhancement of irradiation time up to $35 \mathrm{~min}$. Regarding the influence of $\mathrm{pH}$ on $\mathrm{MO}$ degradation rate using $\mathrm{TiO}_{2}$ nanoparticles and modified MWCNTs, it is clear that the maximum and 
minimum degradation rate is attributed to the suspension with $\mathrm{pH}=3$ and $\mathrm{pH}=7$. It means that at the same time of irradiation, the concentration of $\mathrm{MO}$ in the suspension with acidic condition $(\mathrm{pH}=3)$ is lower than that of neutral condition ( $\mathrm{pH}=7)$. Based on the slop of these two curves, it can be observed that the variation of $\mathrm{MO}$ concentration with respect to the irradiation time is more than that of $\mathrm{pH}$. Therefore, it can be deducted that the influence of irradiation time is more than $\mathrm{pH}$. The same results is observed in ANOVA.

\section{Conclusions}

$\mathrm{TiO}_{2}$ nanoparticles and modified MWCNTs are prepared via hydrolysis method. The XRD patterns of as prepared samples show that the structure of $\mathrm{TiO}_{2}$ nanoparticles is anatase and rutile. The comparison between degradation rates of $\mathrm{MO}$ using synthesized photocatalysts reveals that the modified MWCNTs have higher photocatalytic performance rather than $\mathrm{TiO}_{2}$ nanoparticles. The investigation of degradation rate based on the ANOVA show that the variation of level of each factor could significantly change the response. Meanwhile, at $5 \%$ level of probability, the proposed models are significant. So that, the graphical results show that there is a good consistency among actuals and predicted values of degradation rate of $\mathrm{MO}$ using the models. The response surface method validates the ANOVA results.

\section{Declarations}

\section{Acknowledgements}

We are thankful from boss of central research laboratory of Esfarayen University of Technology.

\section{References}

[1] N. Bouazza, M. Ouzzine, M. A. L.-R. denas, D. Eder, and A. Linares-Solano, "TiO 2 nanotubes and CNT- $\mathrm{TiO}_{2}$ hybrid materials for the photocatalytic oxidation of propene at low concentration," Applied Catalysis B: Environmental, vol. 92, pp. 377-383, 2009.

[2] Y. Dong, D. Tang, and C. Li, "Photocatalytic oxidation of methyl orange in waterphase by immobilized $\mathrm{TiO}_{2}$-carbon nanotube nanocomposite photocatalyst," Appl. Surf. Sci., vol. 296 pp. 1-7, 2014.

[3] S. Abbasi, M.-S. Ekrami-Kakhki, and M. Tahari, "Modeling and predicting the photodecomposition of methylene blue via $\mathrm{ZnO}^{-\mathrm{SnO}_{2}}$ hybrids using design of experiments (DOE) "Journal of Materials Science: Materials in Electronics, vol. 28, pp. 15306-15312, 2017.

[4] G. Zhu, H. Wang, G. Yang, L. Chen, P. Guo, and L. Zhang, "A facile synthesis of ZnO/CNTs hierarchical mircosphere composites with enhanced photocatalytic degradation of methylene blue," RSC Advances, vol. 5, pp. 72476-72481, 2015. 
[5] A. Ghaderi, S. Abbasi, and F. Farahbod, "Synthesis, characterization and photocatalytic performance of modified $\mathrm{ZnO}$ nanoparticles with $\mathrm{SnO}_{2}$ nanoparticles," Materials Research Express, vol. 5, p. 065908, 2018.

[6] N. Roozban, S. Abbasi, and M. Ghazizadeh, "The experimental and statistical investigation of the photo degradation of methyl orange using modified MWCNTs with different amount of ZnO nanoparticles," Journal of Materials Science: Materials in Electronics, vol. 28, pp. 7343-7352, 2017.

[7] A. Ghaderi, S. Abbasi, and F. Farahbod, "Synthesis of $\mathrm{SnO}_{2}$ and $\mathrm{ZnO}$ Nanoparticles and $\mathrm{SnO}_{2}-\mathrm{ZnO}$ Hybrid for the Photocatalytic Oxidation of Methyl Orange," Iranian Journal of Chemical Engineering, vol. 12, pp. 96-105, 2015.

[8] H. Wang, S. Baek, J. Lee, and S. Lim, "High photocatalytic activity of silver-loaded $\mathrm{ZnO}^{-\mathrm{SnO}_{2}}$ coupled catalysts," Chemical Engineering Journal, vol. 146, pp. 355-361, 2009.

[9] N. Zhou, L. Polavarapu, N. Gao, Y. Pan, P. Yuan, Q. Wang, and Q.-H. Xu, "TiO 2 coated Au/Ag nanorods with enhanced photocatalytic activity under visible light irradiation," Nanoscale, vol. 5, pp. 4236$41,2013$.

[10] S. Abbasi, M. Hasanpour, and M. S. E. Kakhki, "Removal efficiency optimization of organic pollutant (methylene blue) with modified multi-walled carbon nanotubes using design of experiments (DOE)," Journal of Materials Science: Materials in Electronics, vol. 28, pp. 9900-9910, 2017.

[11] S. Abbasi, "Investigation the Kinetic Reaction Variation of the Methyl Orange Decomposition Using Decorated Multi-Walled Carbon Nanotubes with ZnO Nanoparticles, Influence of Nanoparticle Content," Journal of Environmental Health Engineering, vol. 5, pp. 113-122, 2018.

[12] S. Abbasi, F. Ahmadpoor, M. Imani, and M.-S. Ekrami-Kakhki, "Synthesis of magnetic $\mathrm{Fe}_{3} \mathrm{O}_{4} @ \mathrm{ZnO} @ g r a p h e n e$ oxide nanocomposite for photodegradation of organic dye pollutant," International Journal of Environmental Analytical Chemistry, 2019.

[13] S. P. Kim, M. Y. Choi, and H. C. Choi, "Characterization and photocatalytic performance of $\mathrm{SnO}_{2}-$ CNTnanocomposites," Applied Surface Science, vol. 357, pp. 302-308, 2015.

[14] S. Abbasi, "Photocatalytic activity study of coated Anatase-Rutile Titania nanoparticles with nanocrystalline tin dioxide based on the statistical analysis " Environmental Monitoring and Assessment, vol. 191, pp. 206-218, 2019.

[15] S. Abbasi, M. Hasanpour, F. Ahmadpoor, M. Sillanpää, D. Dastan, and A. Achour, "Application of the statistical analysis methodology for photodegradation of methyl orange using a new nanocomposite containing modified $\mathrm{TiO} 2$ semiconductor with $\mathrm{SnO}_{2}$," International Journal of Environmental Analytical Chemistry, 2019. 
[16] D. A. Reddy, R. Ma, and T. K. Kim, "Efficient photocatalytic degradation of methyleneblue by heterostructured $\mathrm{ZnO}-\mathrm{RGO} / \mathrm{RuO}_{2}$ nanocomposite under thesimulated sunlight irradiation," Ceram. Int., vol. 41, pp. 6999-7009, 2015.

[17] M. Ahmad, E. Ahmed, Z. L. Hong, X. L. Jiao, T. Abbas, and N. R. Khalid, "Enhancementin visible lightresponsive photocatalytic activity byembedding Cu-doped $\mathrm{ZnO}$ nanoparticles on multi-walled carbonnanotubes," Appl. Surf. Sci. , vol. 285, pp. 702-712, 2013.

[18] S. Abbasi, "Investigation of the enhancement and optimization of the photocatalytic activity of modified $\mathrm{TiO}_{2}$ nanoparticles with $\mathrm{SnO}_{2}$ nanoparticles using statistical method," Materials Research Express, vol. 5, p. 066302, 2018.

[19] S. Abbasi, S. M. Zebarjad, and S. H. N. Baghban, "Decorating and Filling of Multi-Walled Carbon Nanotubes with $\mathrm{TiO}_{2}$ Nanoparticles via Wet Chemical Method," Engineering, vol. 5, pp. 207-212, 2013.

[20] S. Abbasi, S. M. Zebarjad, S. H. N. Baghban, and A. Youssefi, "Synthesis of $\mathrm{TiO}_{2}$ nanoparticles and decorated multiwalled carbon nanotubes with various content of rutile titania," Synthesis and Reactivity in Inorganic, Metal-Organic, and Nano-Metal Chemistry, vol. 45, pp. 1539-1548, 2015.

[21] N. Roozban, S. Abbasi, and M. Ghazizadeh, "Statistical analysis of the photocatalytic activity of decorated Multi-Walled carbon nanotubes with ZnO nanoparticles," Journal of Materials Science: Materials in Electronics, vol. 28, pp. 6047-6055, 2017.

[22] S. Abbasi, "Photocatalytic Removal of Methyl Orange in Suspension Containing $\mathrm{ZnO}$ and $\mathrm{SnO}_{2}$ Nanoparticles and Investigation the Influence of Effective Variables on the Process," Iranian Journal of Health and Environment, vol. 9, pp. 433-442, 2016.

[23] S. Abbasi, "Adsorption of Dye Organic Pollutant Using Magnetic ZnO Embedded on the Surface of Graphene Oxide," Journal of Inorganic and Organometallic Polymers and Materials, 2019.

[24] S. Abbasi and M. Hasanpour, "The effect of $\mathrm{pH}$ on the photocatalytic degradation of methyl orange using decorated $\mathrm{ZnO}$ nanoparticles with $\mathrm{SnO}_{2}$ nanoparticles," Journal of Materials Science: Materials in Electronics, vol. 28, pp. 1307-1314, 2017.

[25] H. Yuan and J. Xu, "Preparation, characterization and photocatalytic activity of nanometer $\mathrm{SnO}_{2}, "$ Int. J. Chem. Eng. Appl., vol. 3, pp. 214- 246, 2010.

[26] S. Abbasi, a. M.-S. Ekrami-Kakhki, and M. Tahari, "The influence of ZnO nanoparticles amount on the optimisation of photo degradation of methyl orange using decorated MWCNTs," Progress in Industrial Ecology - An International Journal, vol. 13, pp. 3-15, 2019.

[27] S. Abbasi and M. Hasanpour, "Variation of the photocatalytic performance of decorated MWCNTs (MWCNTs-ZnO) with pH for photo degradation of methyl orange," Journal of Materials Science: Materials 
in Electronics, vol. 28, pp. 11846-11855, 2017.

[28] M.-S. Ekrami-Kakhki, S. Abbasi, and N. Farzaneh, "Statistical Analysis of the Electrocatalytic Activity of Pt Nanoparticles Supported on Novel Functionalized Reduced Graphene Oxide-Chitosan for Methanol Electrooxidation," Electronic Materials Letters, vol. 14, pp. 70-78, 2018.

[29] M. Namvar-Mahboub and M. Pakizeh, "Optimization of preparation conditions of polyamide thin film composite membrane for organic solvent nanofiltration," Korean J. Chem. Eng., vol. 31, pp. 327-337, 2014.

[30] M.-S. Ekrami-Kakhki, S. Abbasi, and N. Farzaneh, "Design of Experiments Methodology to Investigate Methanol Electrooxidation on Pt Nanoparticles Supported Novel Functionalized Reduced Graphene Oxide," Analytical \& Bioanalytical Electrochemistry, vol. 10, pp. 1548-1561, 2018.

[31] A. Kazemi-Beydokhti, H. A. Namaghi, M. A. H. Asgarkhani, and S. Z. Heris, "PREDICTION OF STABILITY AND THERMAL CONDUCTIVITY OF $\mathrm{SnO}_{2}$ NANOFLUID VIA STATISTICAL METHOD AND AN ARTIFICIAL NEURAL NETWORK," Brazilian Journal of Chemical Engineering, vol. 32, pp. 903 - 917, 2015.

[32] A. Ahmad, M. I. Ahmad, M. Younas, H. Khan, and M. u. H. Shah, "A Comparative Study of Alkaline Hydrolysis of Ethyl Acetate Using Design of Experiments " Iran. J. Chem. Chem. Eng., vol. 32, pp. 33-47, 2013.

\section{Figures}




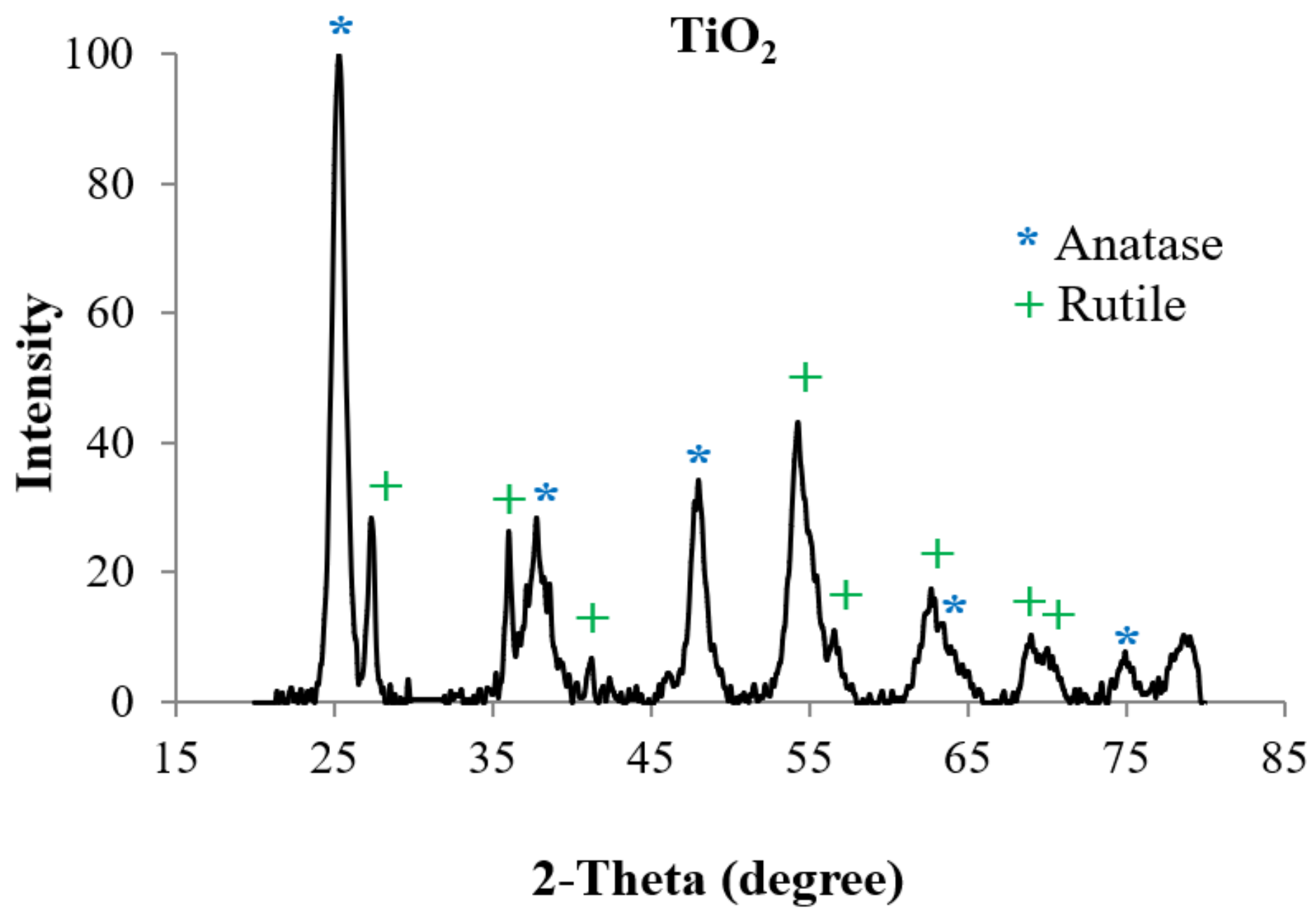

Figure 1

XRD pattern of TiO2 nanoparticles. 


\section{Functionalized MWCNTs}

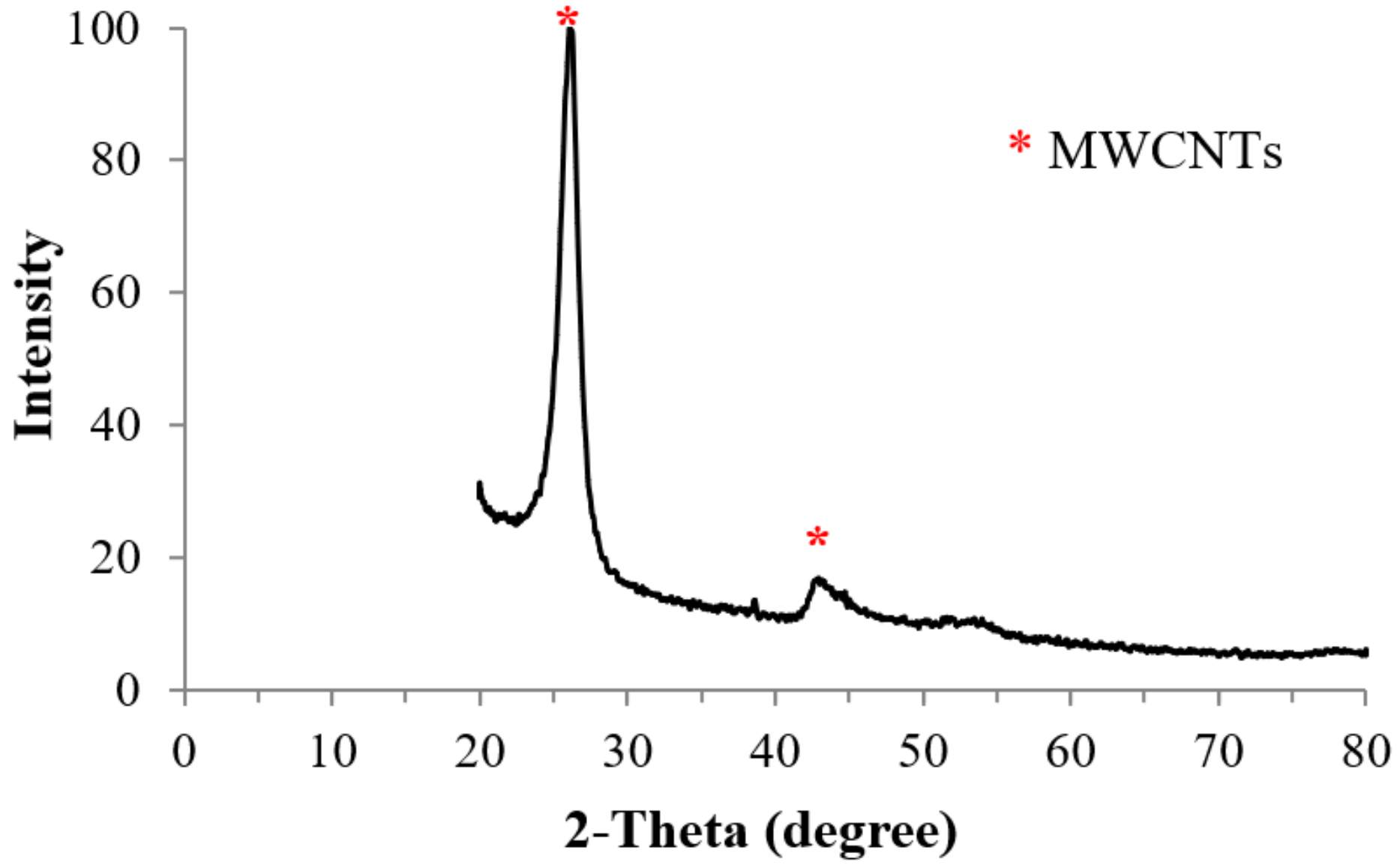

Figure 2

XRD pattern of functionalized MWCNTs. 


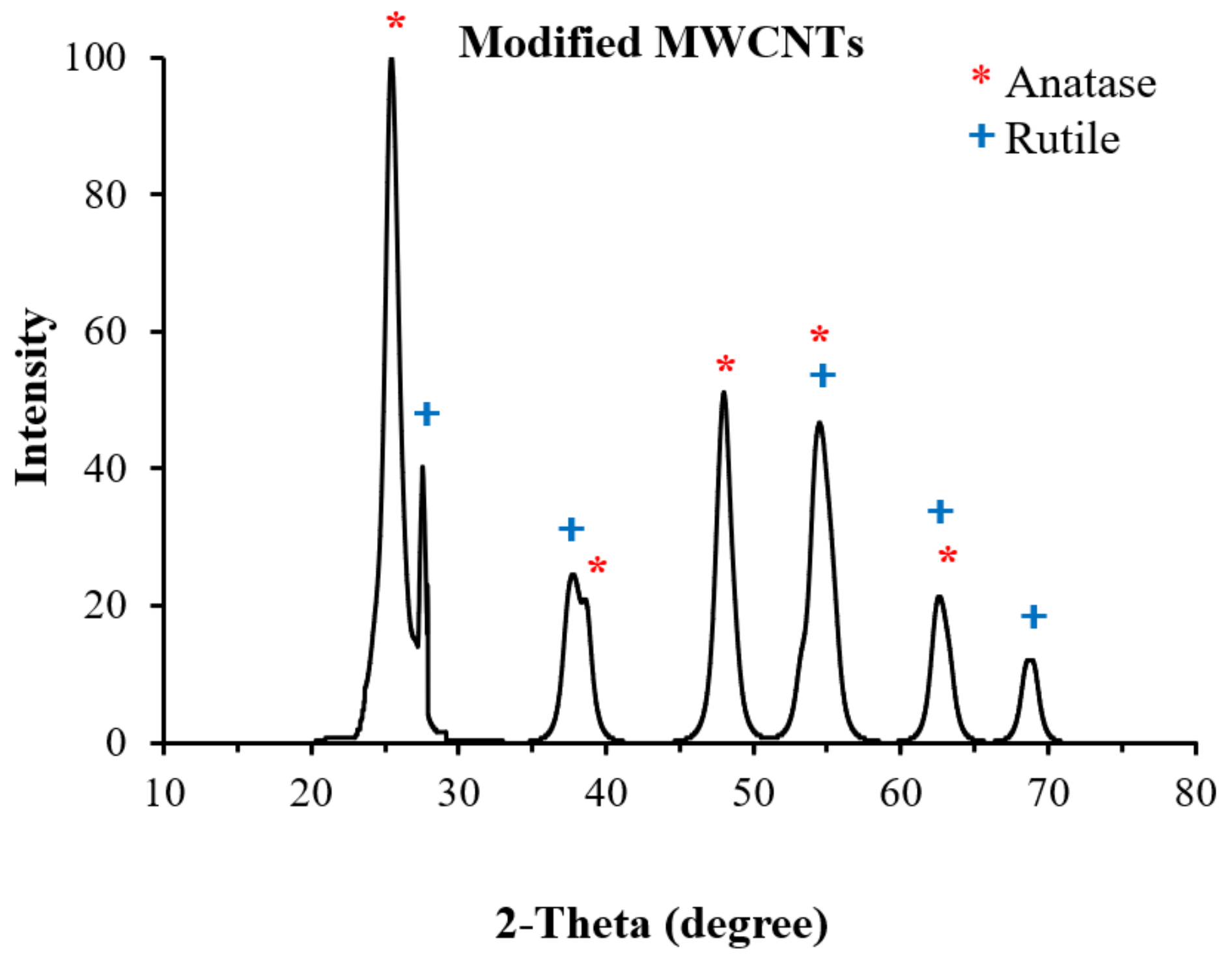

Figure 3

XRD pattern of modified MWCNTs with TiO2 nanoparticles. 


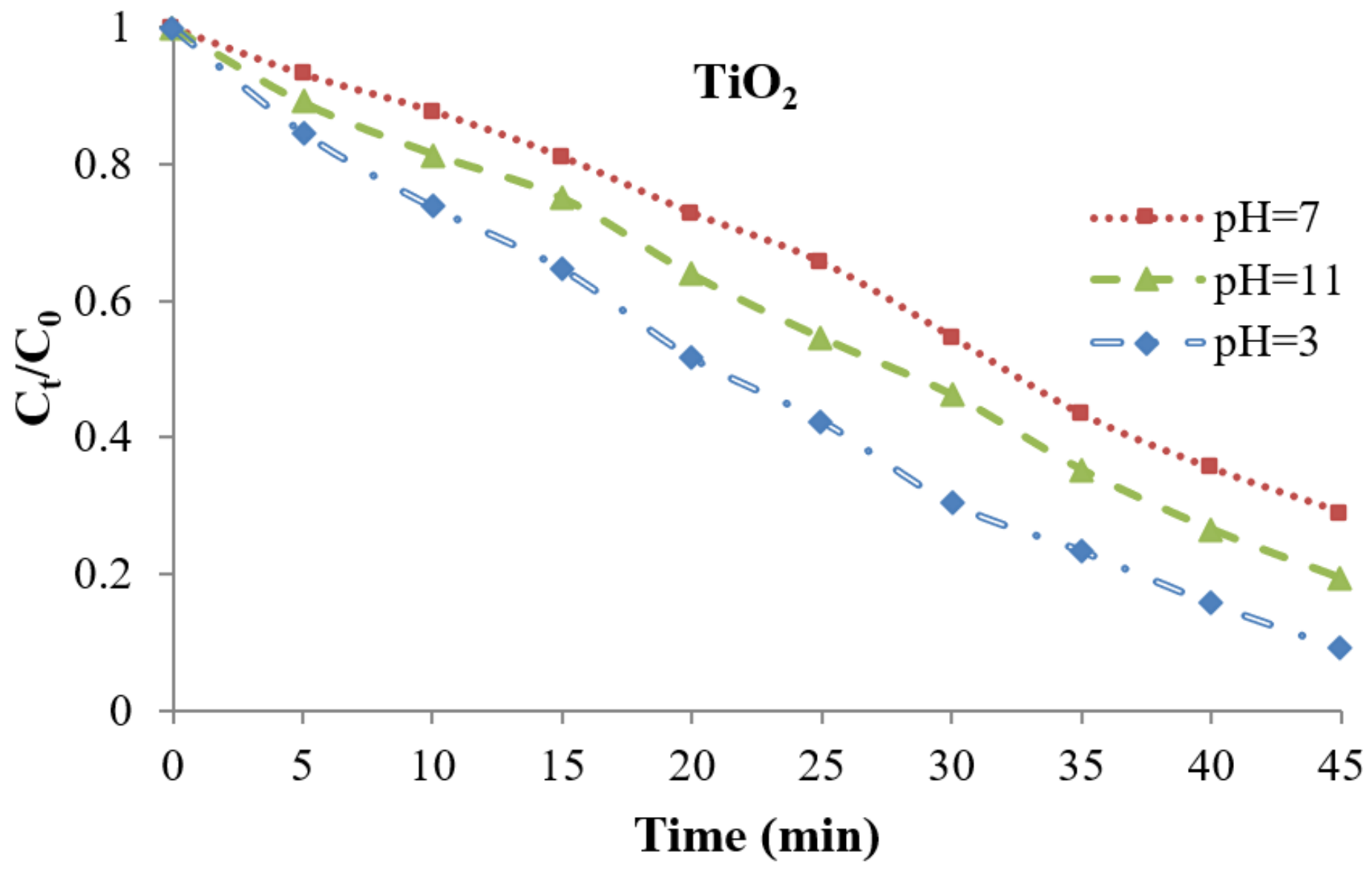

Figure 4

The variation of $\mathrm{MO}$ concentration with respect to the irradiation time and $\mathrm{pH}$ using $\mathrm{TiO} 2$ nanoparticles as photocatalyst. 


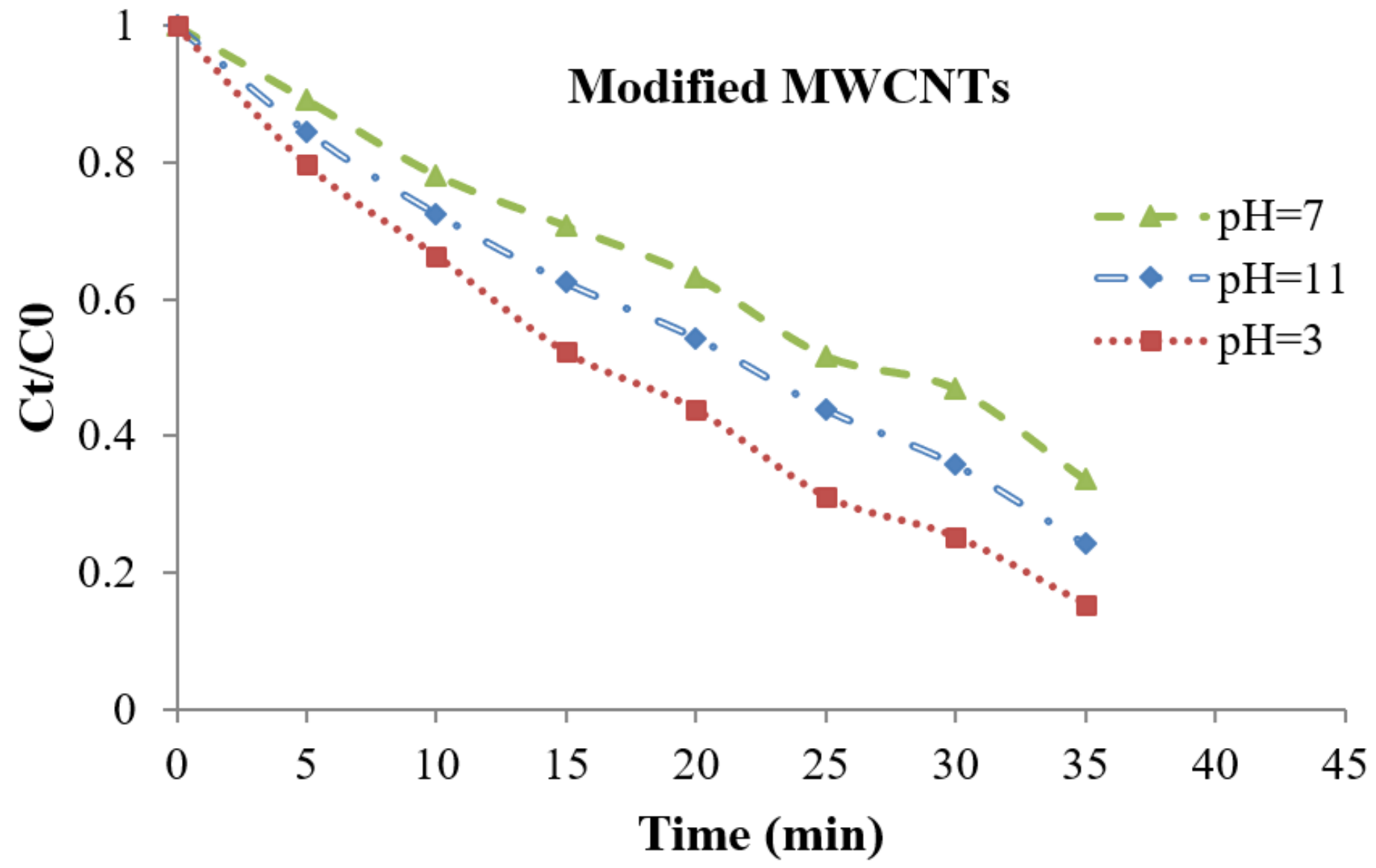

Figure 5

The variation of $\mathrm{MO}$ concentration with respect to the irradiation time and $\mathrm{pH}$ using modified MWCNTs with $\mathrm{TiO} 2$ as photocatalyst. 

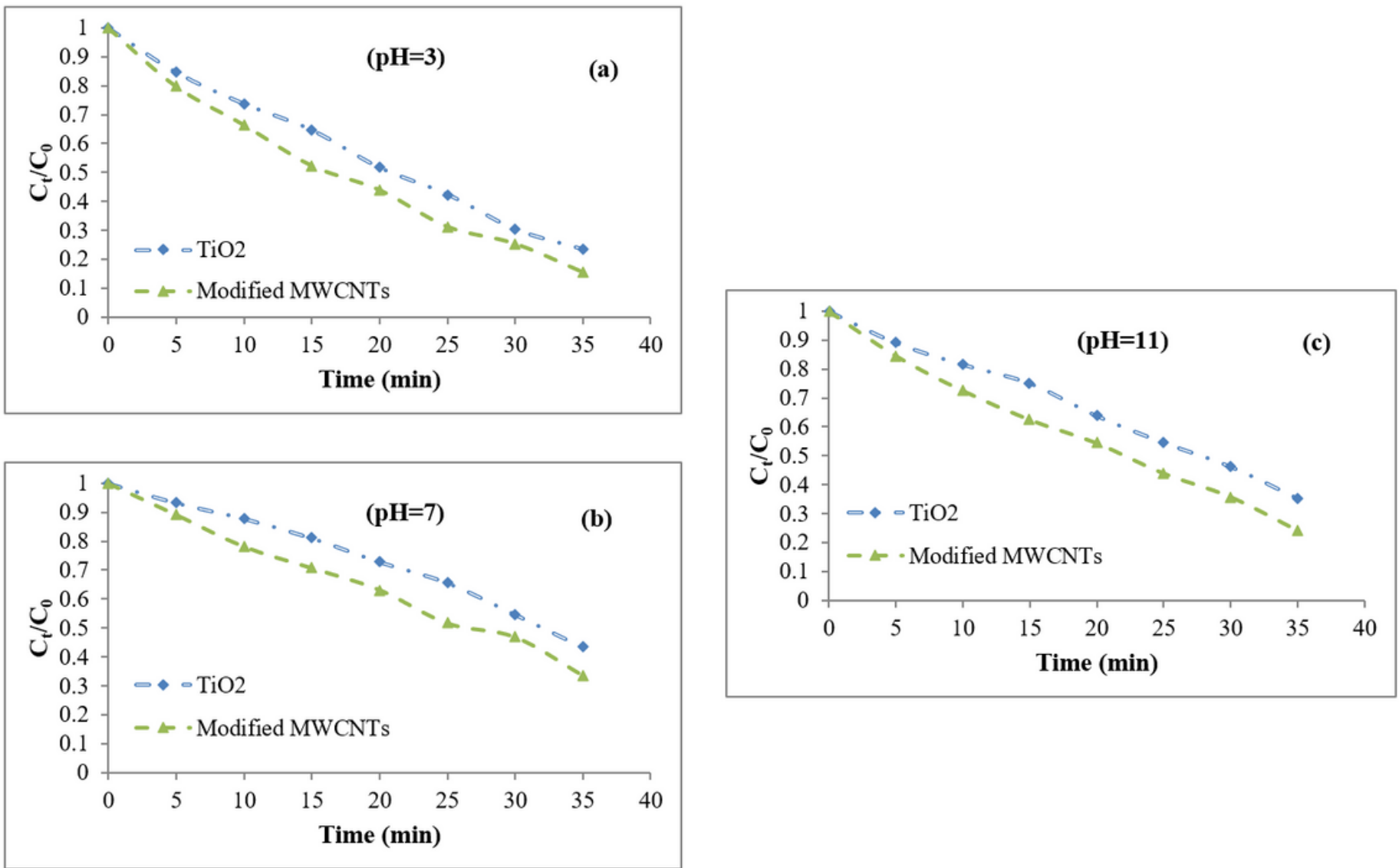

\section{Figure 6}

The comparison between variation of $\mathrm{MO}$ concentration with respect to the irradiation time using TiO2 nanoparticles and modified MWCNTs at different $\mathrm{pH}, \mathrm{a}) \mathrm{pH}=3, \mathrm{~b}) \mathrm{pH}=7, \mathrm{c}) \mathrm{pH}=11$. 


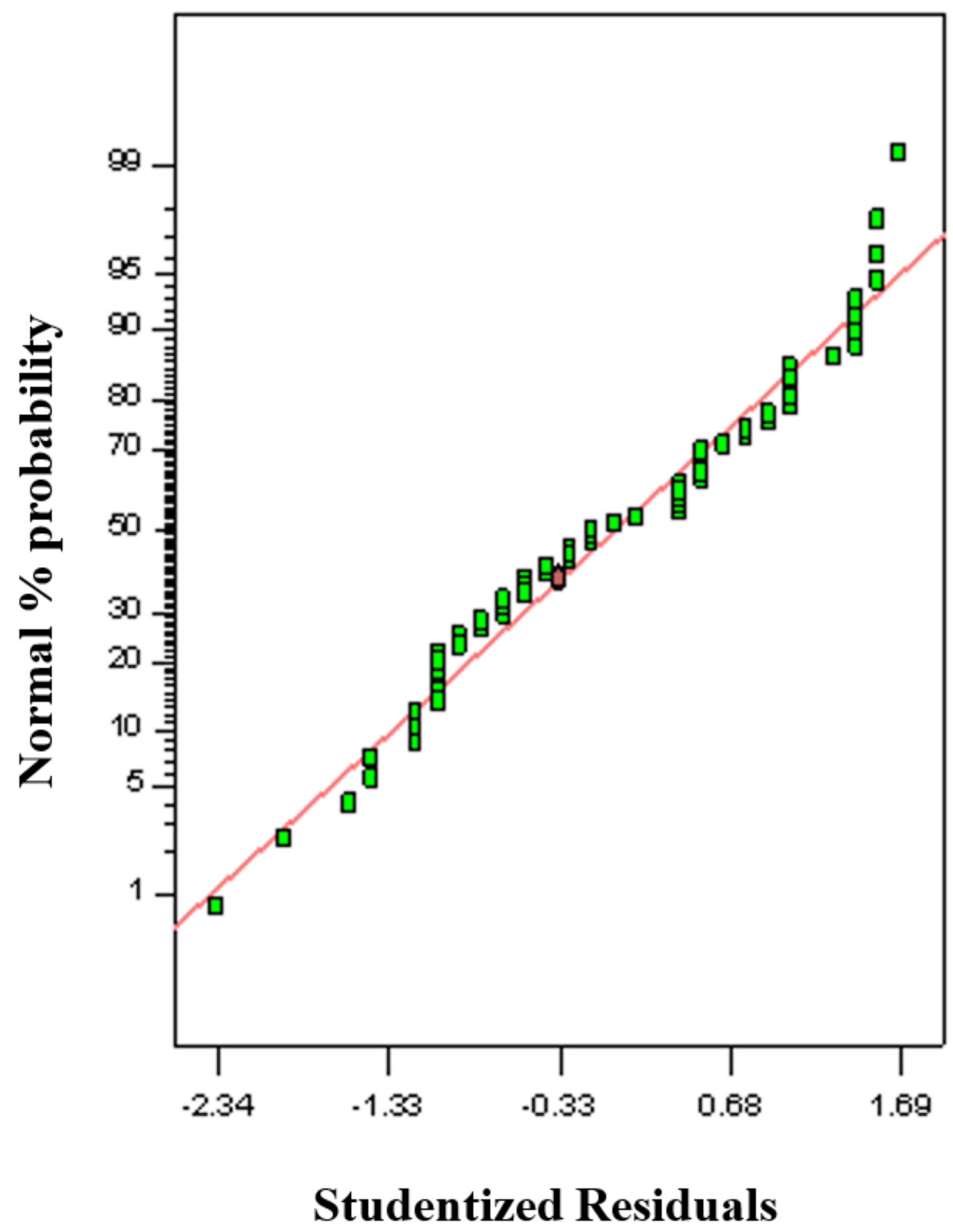

Figure 7

Normal plot of residuals for degradation rate of $\mathrm{MO}$ using $\mathrm{TiO} 2$ nanoparticles. 


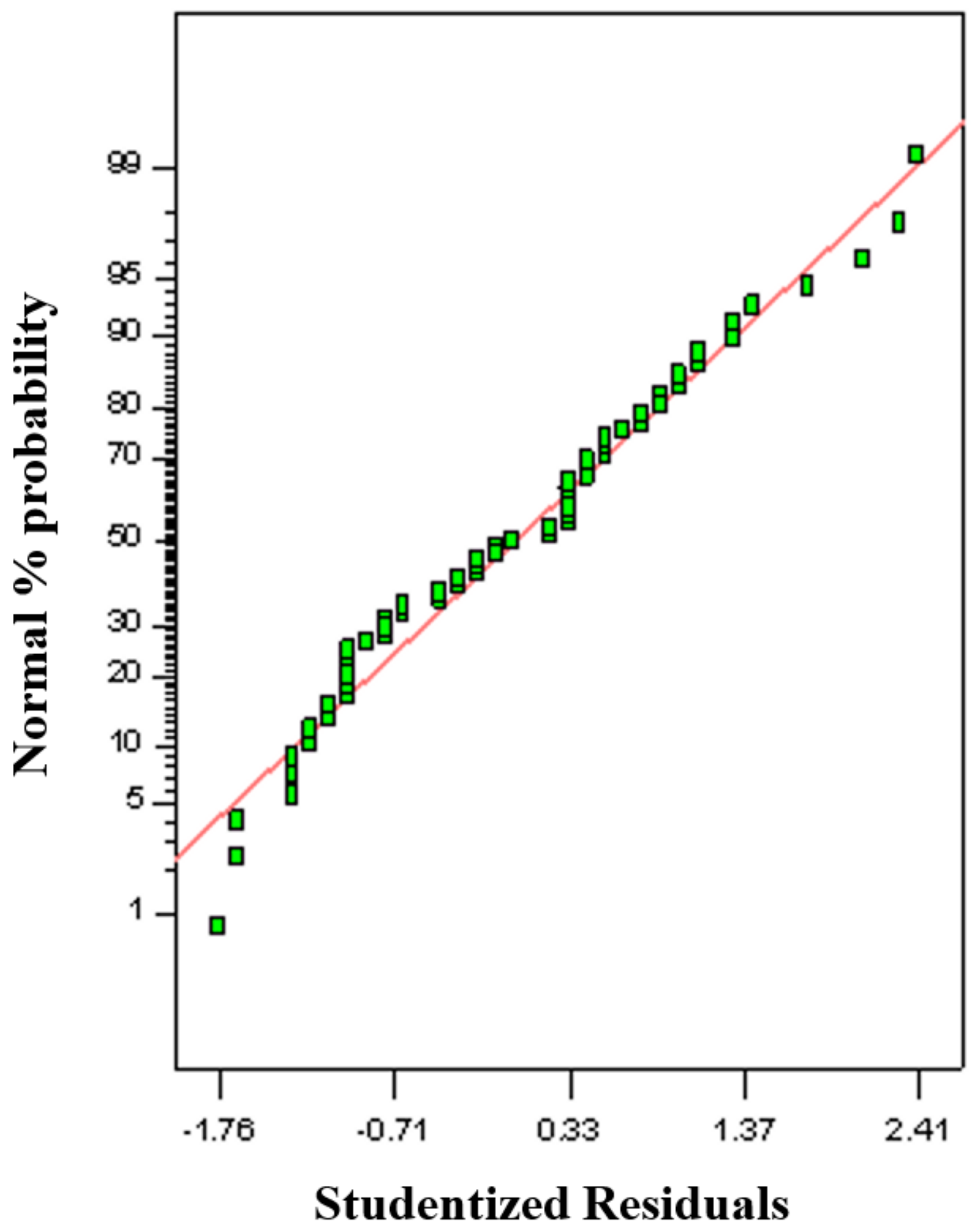

Figure 8

Normal plot of residuals for degradation rate of MO using modified MWCNTs with TiO2 nanoparticles. 


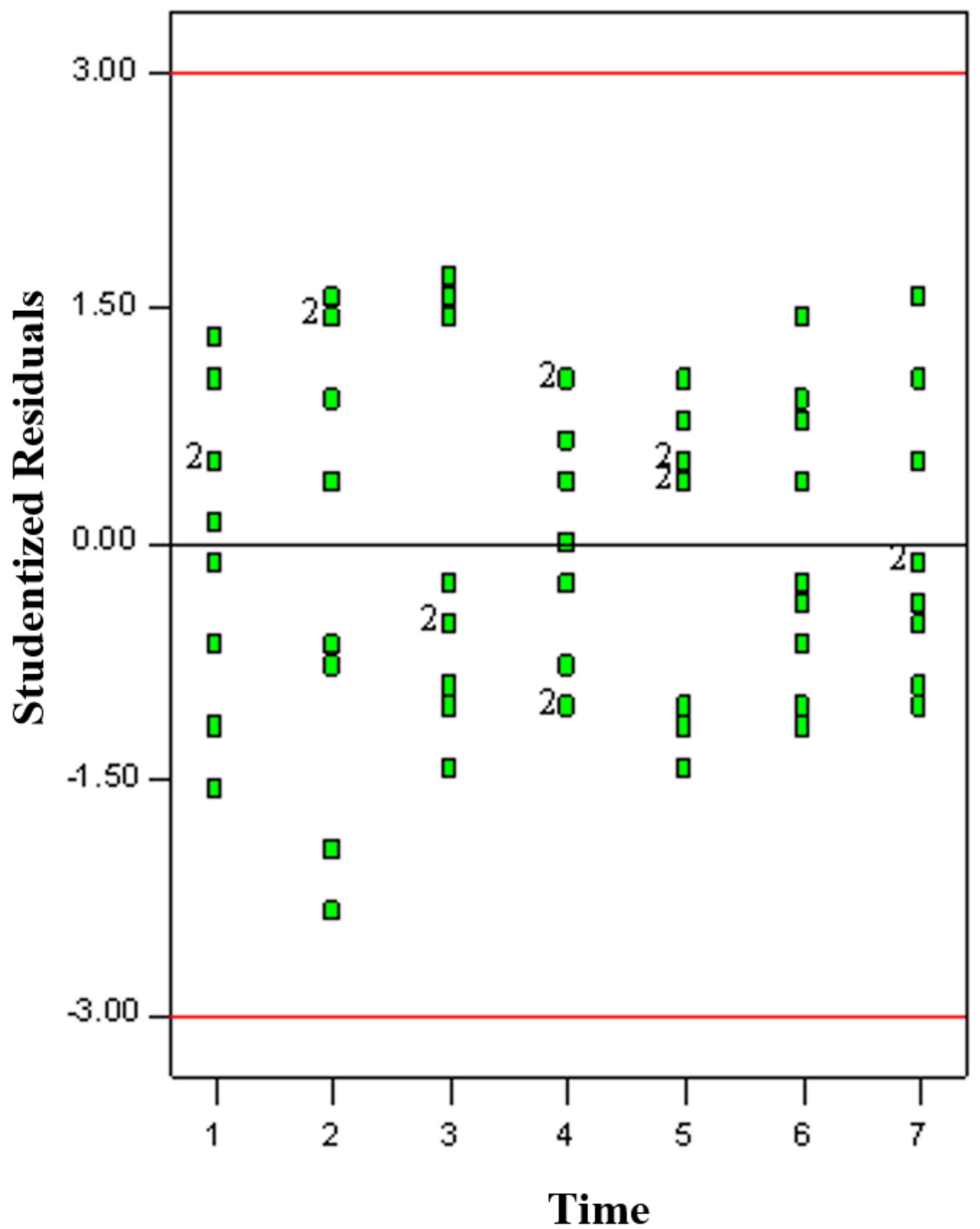

Figure 9

Plot of studentized residual versus time of irradiation in suspension containing TiO2 nanoparticles. 


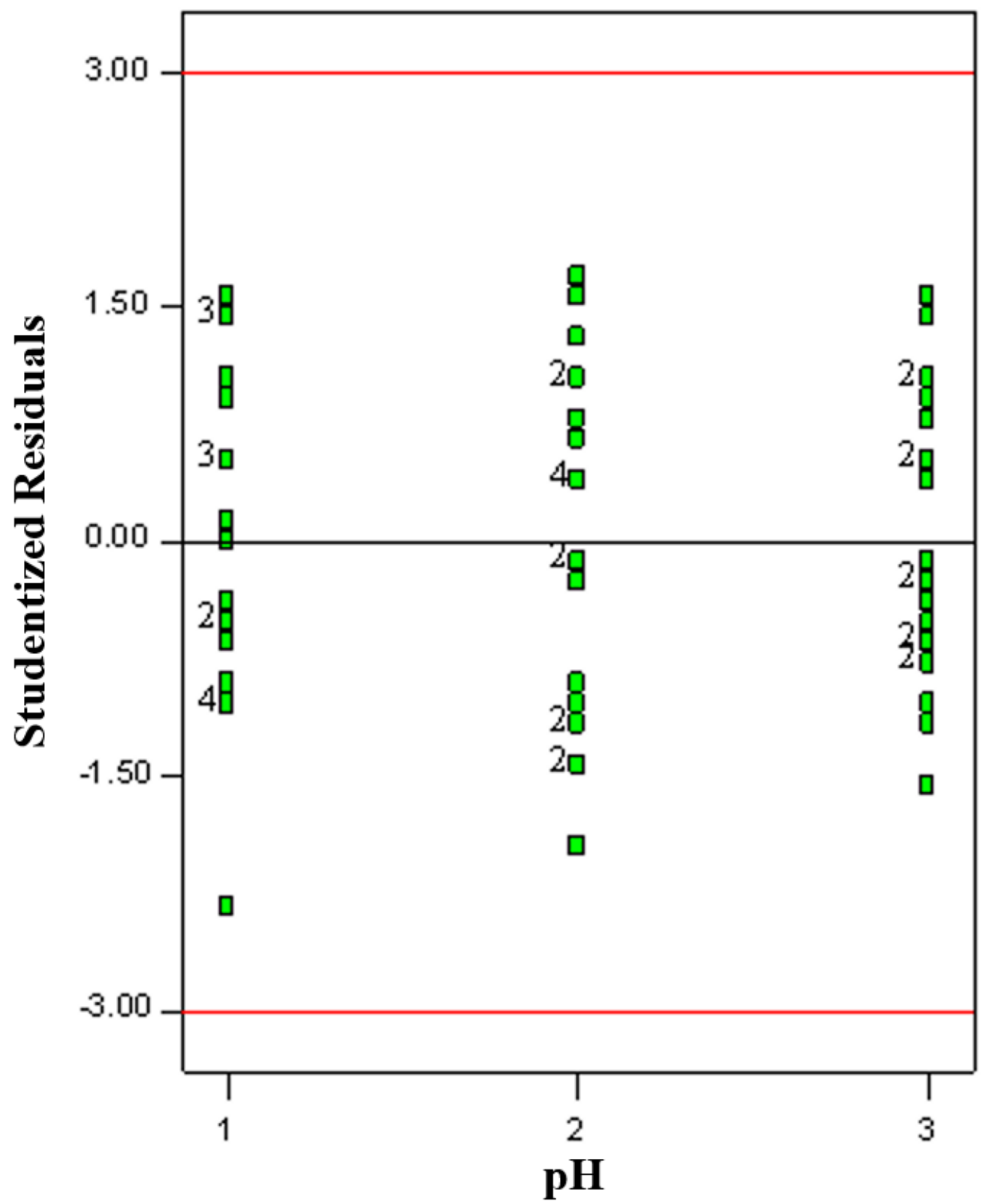

Figure 10

Plot of studentized residual versus $\mathrm{pH}$ in suspension containing TiO2 nanoparticles. 


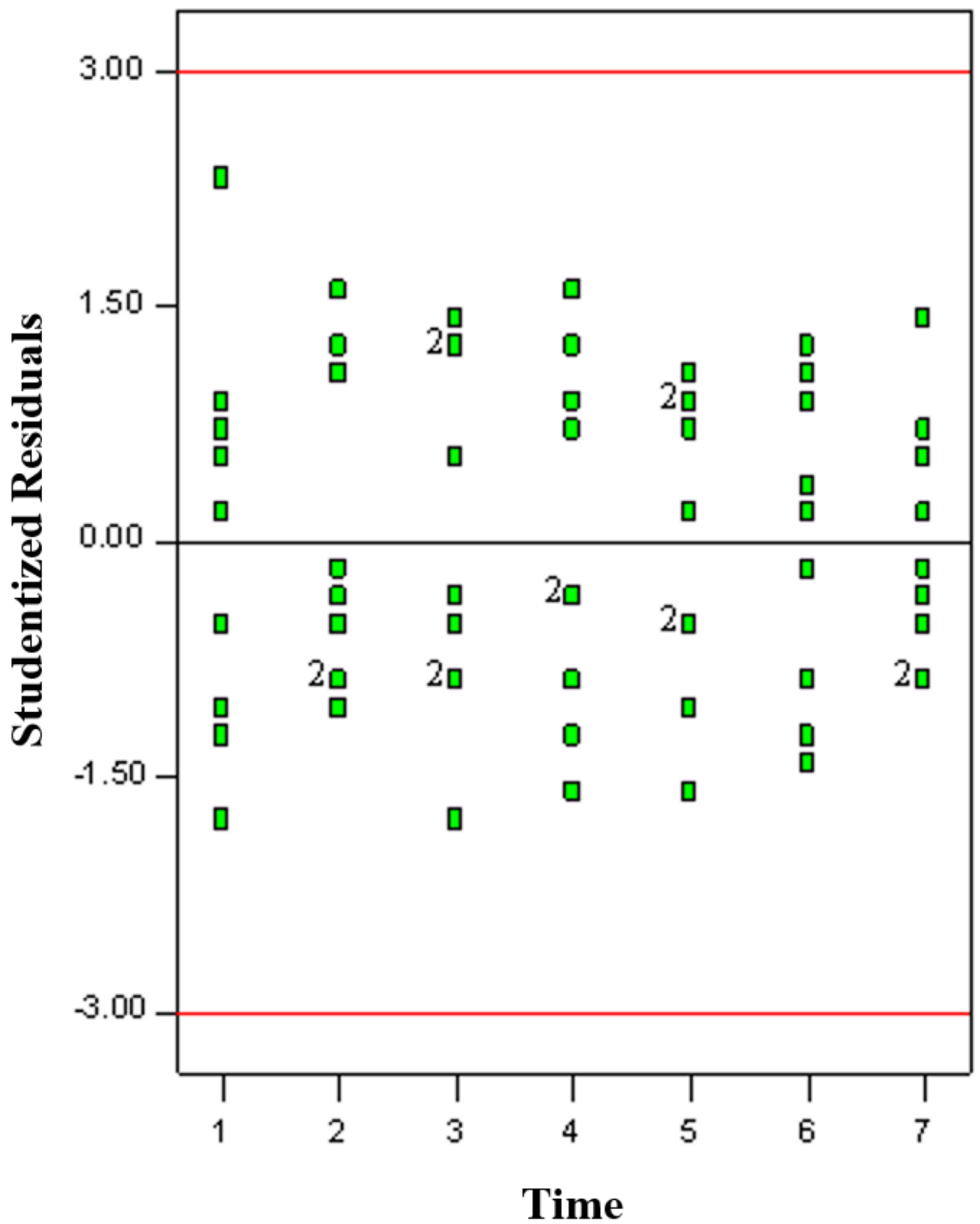

Figure 11

Plot of studentized residual versus time of irradiation in suspension containing modified MWCNTs with TiO2 nanoparticles. 


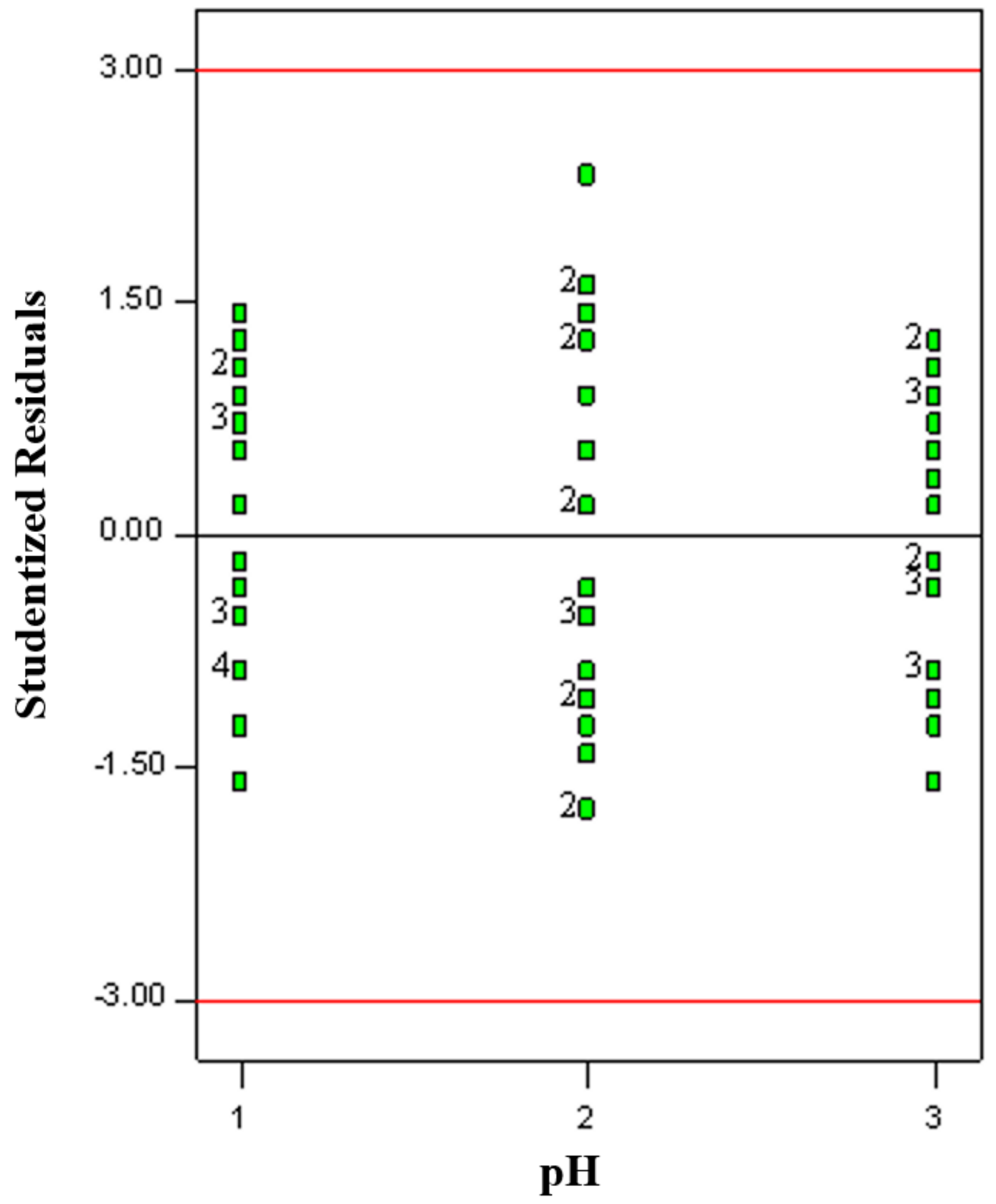

Figure 12

Plot of studentized residual versus $\mathrm{pH}$ in suspension containing modified MWCNTs with TiO2 nanoparticles. 


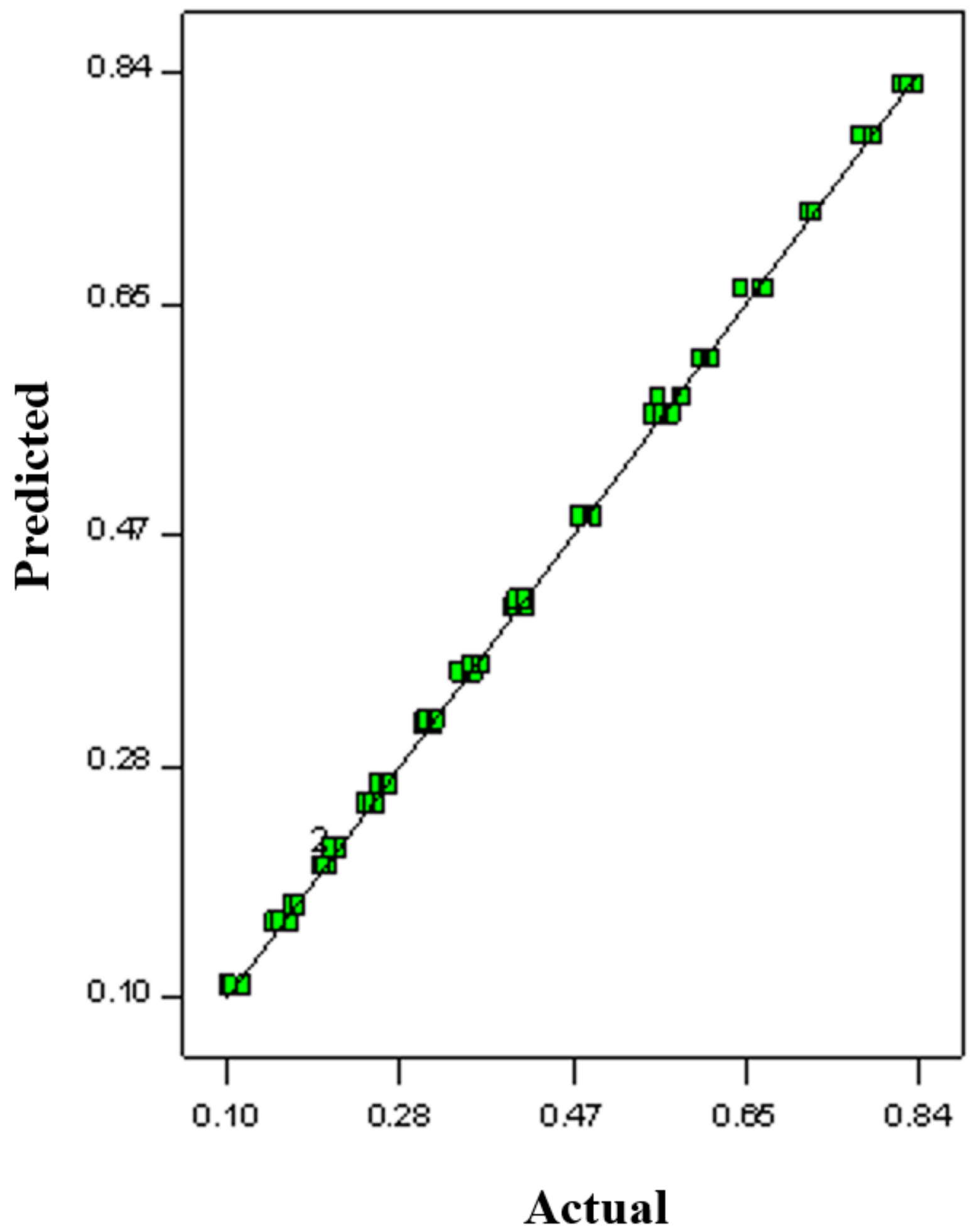

Figure 13

Predicted versus actual value of $\mathrm{MO}$ degradation rate using TiO2 nanoparticles. 


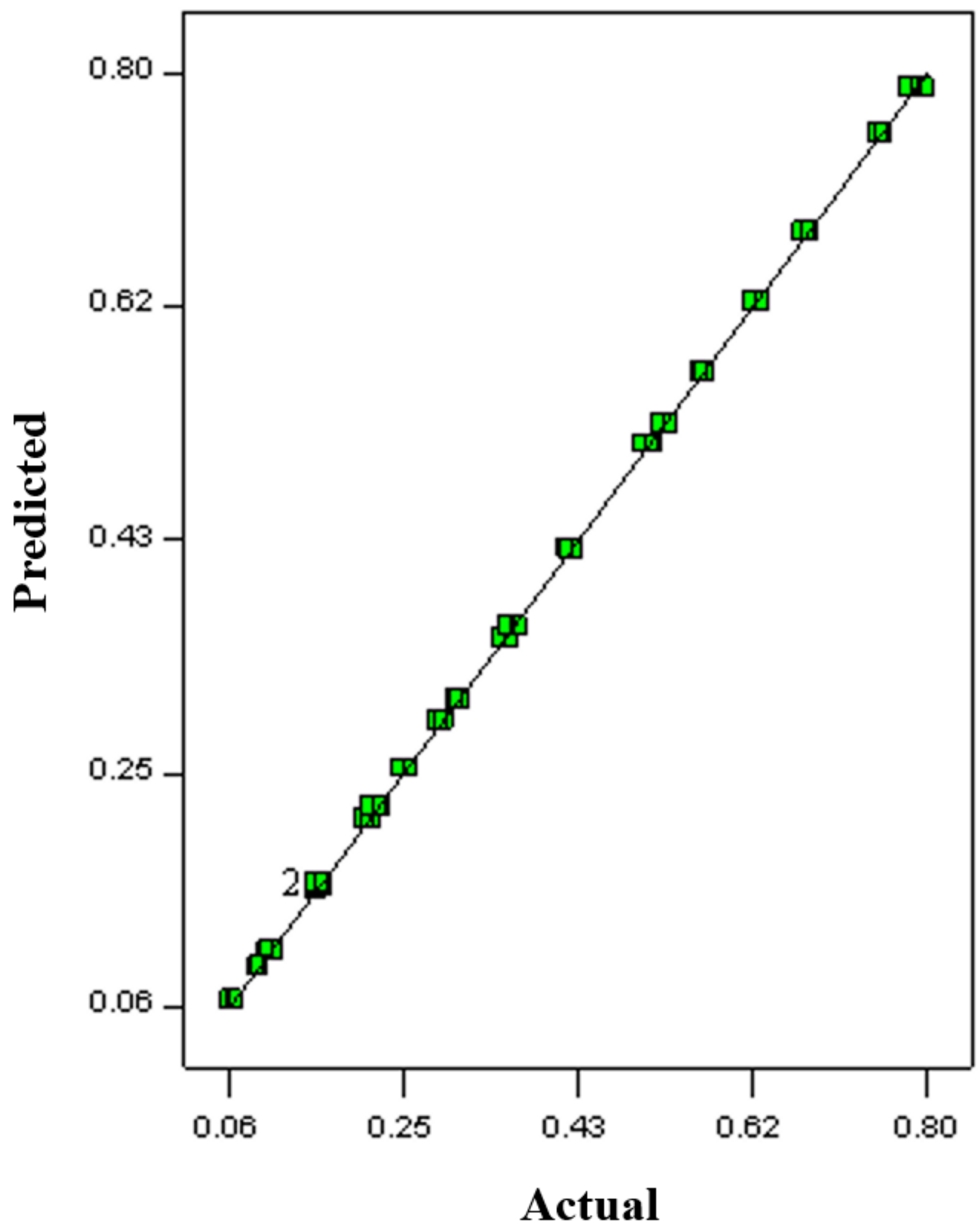

Figure 14

Predicted versus actual value of MO degradation rate using modified MWCNTs with TiO2 nanoparticles. 


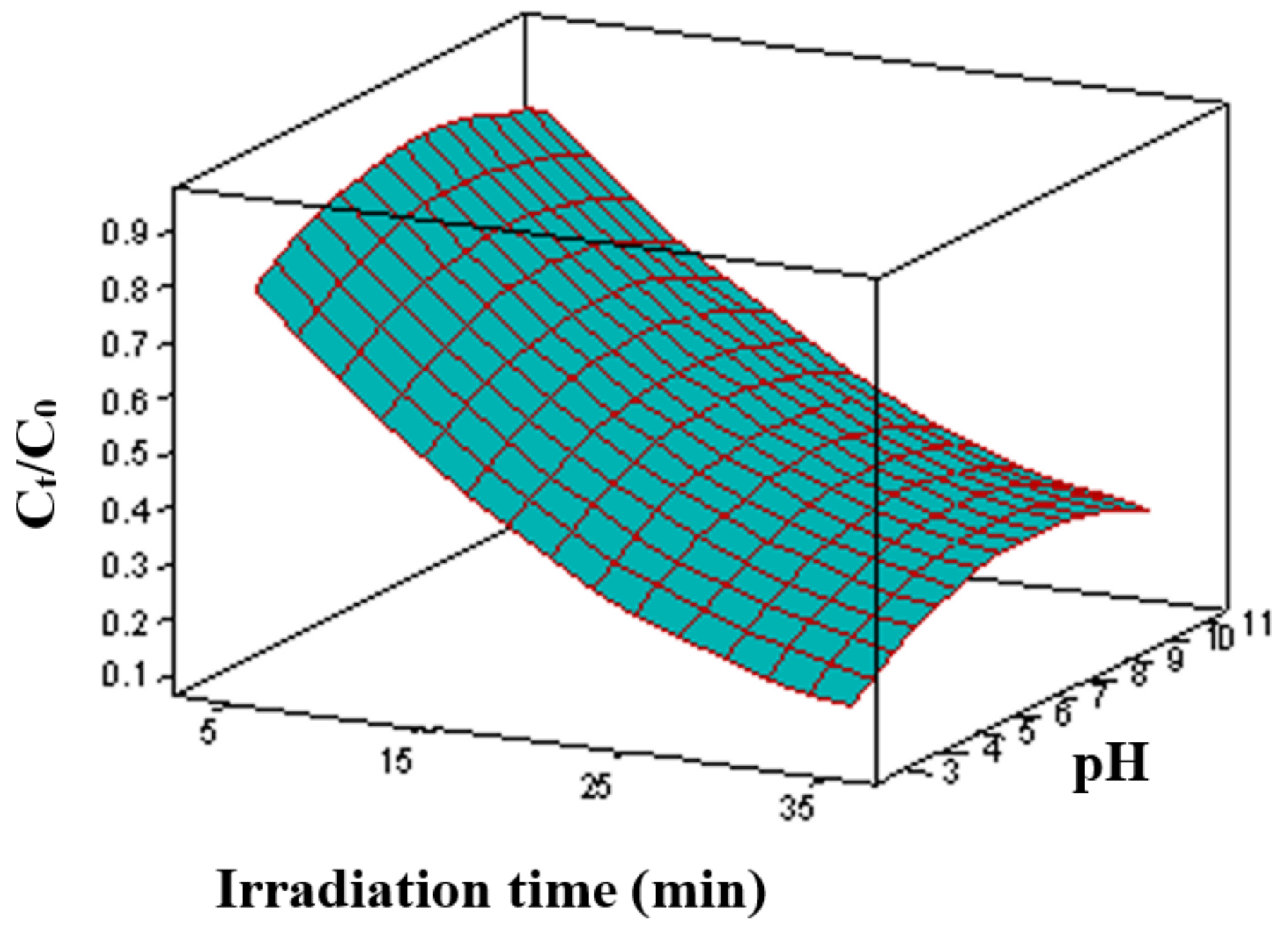

Figure 15

Response surface of $\mathrm{MO}$ degradation rate using $\mathrm{TiO} 2$ nanoparticles. 


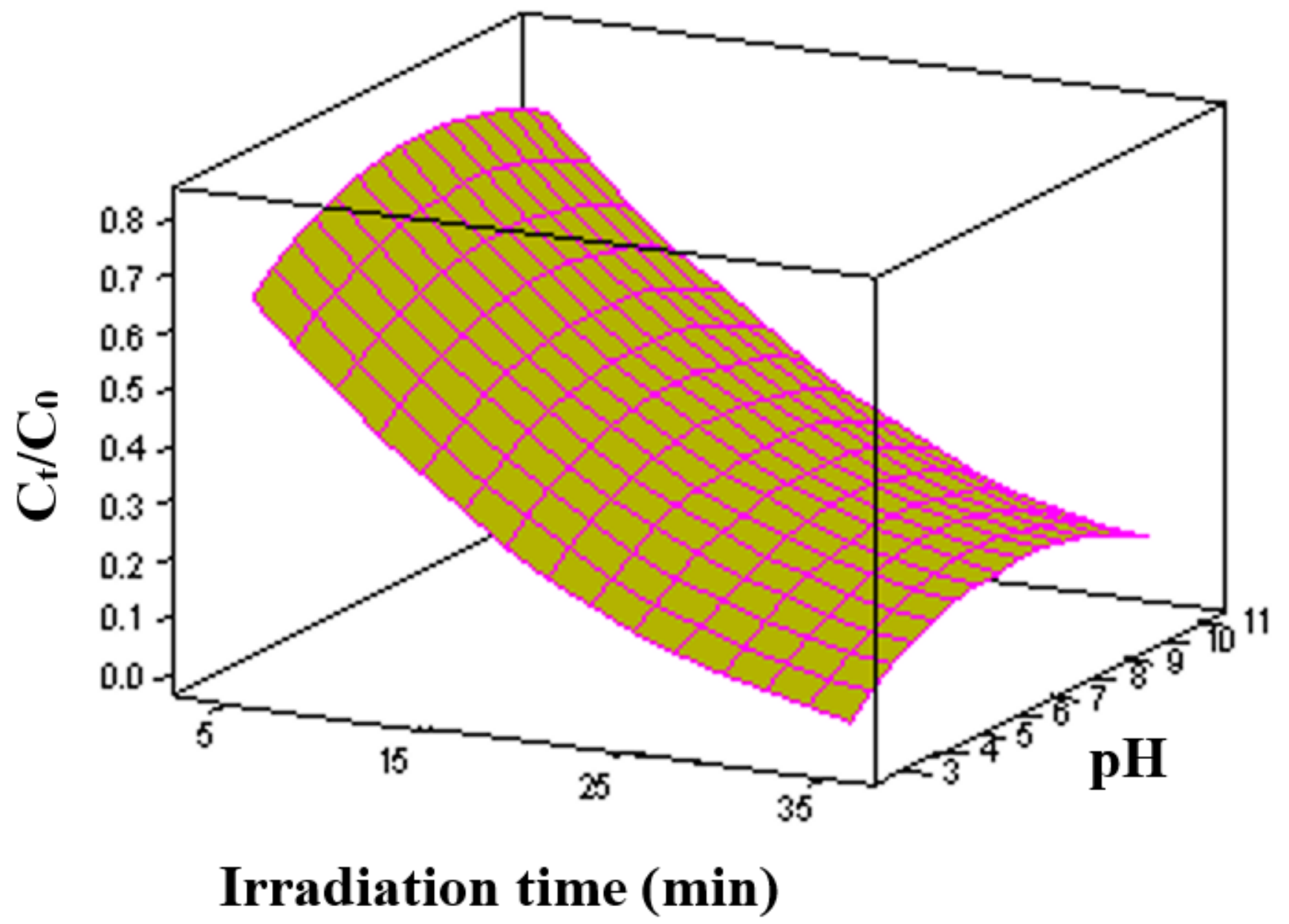

Figure 16

Response surface of $\mathrm{MO}$ degradation rate using MWCNTs with TiO2 nanoparticles. 